ISSN: 1813-162X (Print) ; 2312-7589 (Online)
available online at: http://www.tj-es.com Tikrit Journal of Engineering Sciences

\title{
The Effect of Pads Number and Their Tilt Angles on the Bearing Stiffness
}

\section{Ibrahem Ali Muhsin*}

Department of Mechanical Engineering College of Engineering

Tikrit University

Salahaldeen

Iraq

\section{Keywords:}

Tribology

tilted pads journal bearing

bearing stiffness and stability

\section{A R T I C L E I N F O}

\section{Article history:}

Received 24 September 2017

Accepted 29 July 2018

Available online $\quad 01$ December 2018

\section{A B S T R A C T}

In this work a plain (conventional) and a tilted bad bearings are analyzed and studied (both have the same dimensions and work conditions). Three, four and five pads models are studied. The pads are fixed circumferentially in a manner each two close pads are separated with an angle that is the same for all the close pads. Each pad is pivoted in its trailing edge and is facilitated to be tilted around this pivot with small angles. This study was achieved for three values of tilting angles. These angles are, $0.01^{\circ}, 0.011^{\circ}$ and $0.012^{\circ}$. Two dimensions' form of Reynolds equation is used and solved numerically then the stiffness coefficients had been calculated. A comparison had been done between the stiffness coefficients values for the two models (tilted pads and conventional bearings). The results of this comparison was found that (for $n=0.4$ ), are, $+28 \%,+275 \%,+270 \%$ and $-100 \%$ for $K_{\mathrm{sr}}, K_{\mathrm{rr}}, K_{\mathrm{ss}}$ and $K_{\mathrm{rs}}$ respectively. It was noticed that the values of the principal coefficients $K \mathrm{rr}$ and $K_{\mathrm{ss}}$ are increased significantly while the cross coupling coefficient, $\left(K_{\mathrm{rs}}\right)$ is decreased significantly and $\left(K_{\mathrm{sr}}\right)$ is increased slightly. And this is a positive sign for stability improvement. Also it was found that increasing the tilt angle (delta) cause an increase of the stiffness coefficients values. These increases (for $n=0.4$ and changing the tilt angle from 0.010 to 0.011 then to 0.012 respectively) are, $\mathrm{K}_{\mathrm{rr}}=+50 \%,+47 \%, K_{\mathrm{ss}}=+40 \%,+32 \%, K_{\mathrm{sr}}=+33 \%,+42 \%$, and $K_{\mathrm{rs}}=+15 \%,+20 \%$. And since increasing the values of the cross coupling coefficients make the bearing stability worse, so increasing the tilt angle is not a preferable method for improving stability. Changing the number of pads is a better solution and it was found that three pads bearing is the best among them.

(C) 2018 TJES, College of Engineering, Tikrit University

DOI: http://dx.doi.org/10.25130/tjes.25.4.02

تأثثير عدد الوسادات وزوايا ميلانها على معامل نابضية المسند

في هذا البحث تمت در اسة مسند تقليدي وآخر ذو وسادات قابلة للأمالة والضبط حول حافاتها الأمامية. حيث ان كلا المسندين لهما نفس الأبعاد وظروف العمل. تمت در استة

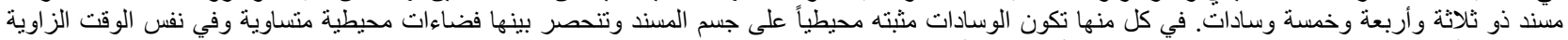

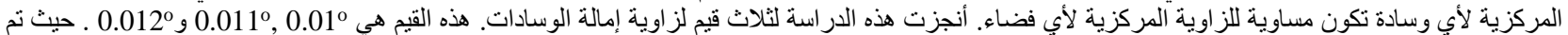

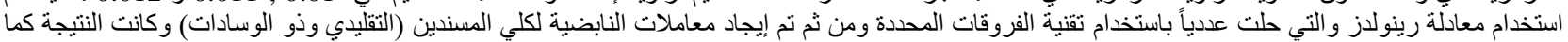

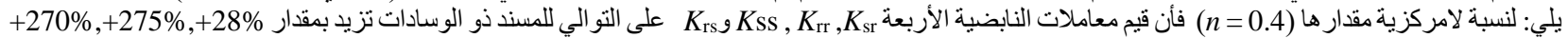

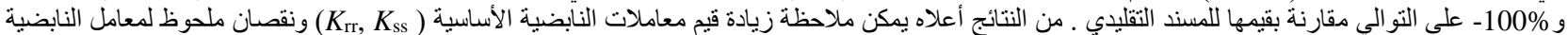

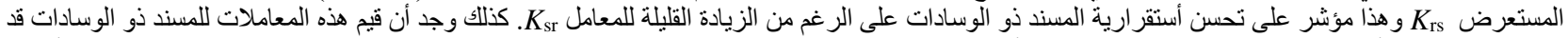

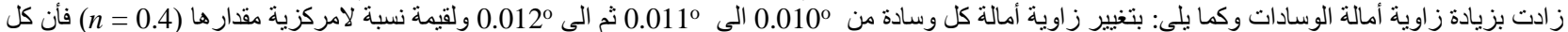

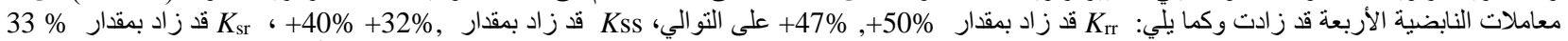

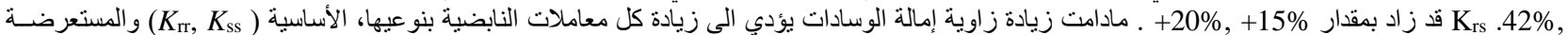

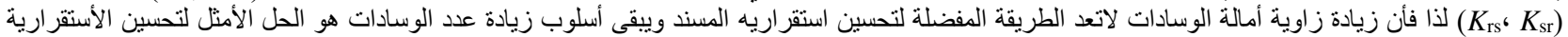
وبالتحديد استخدام المسند ثلاثي الوسادات. 


\section{Nomenclatures \\ $B_{\mathrm{c}} \quad$ bearing center \\ $C_{\mathrm{r}} \quad$ radial clearance, $(\mathrm{m})$ \\ $e \quad$ eccentricity, $(\mathrm{m})$ \\ $F_{\mathrm{r}} \quad$ force parallel to the line of centers, (N) \\ $F_{\mathrm{s}} \quad$ force in the direction perpendicular to the line of centers, $(\mathrm{N})$ \\ $h \quad$ oil film thickness, (m) \\ $J_{\mathrm{c}} \quad$ journal center \\ $J_{\mathrm{cl}} \quad$ journal center position before excitation \\ $J_{\mathrm{c} 2} \quad$ journal center position after excitation \\ $K_{\mathrm{rr}} \quad$ stiffness coefficient in the (r) axis, direction force in the (r) direction, $(\mathrm{N} / \mathrm{m})$ \\ $K_{\mathrm{rs}} \quad$ stiffness coefficient in the (s) direction, force in the $(\mathrm{r})$ direction, $(\mathrm{N} / \mathrm{m})$ \\ $K_{\text {sr }} \quad$ stiffness coefficient in the (r) direction, force in (s) direction, $(\mathrm{N} / \mathrm{m})$ \\ $K_{\text {ss }} \quad$ stiffness coefficient in the (s) direction, force in (s) direction, $(\mathrm{N} / \mathrm{m})$ \\ bearing length, $(\mathrm{m})$ \\ eccentricity ratio \\ journal speed, (rpm) \\ oil film pressure, $(\mathrm{Pa})$ \\ pad angle, (degree) \\ the line of centers axis \\ bearing radius, $(\mathrm{m})$ \\ $R_{\mathrm{p}} \quad$ Pads radius, (m) \\ $s \quad$ the axis perpendicular to the line of centers \\ $U \quad$ journal linear speed, $(\mathrm{m} / \mathrm{sec})$ \\ $W \quad$ external load, $(\mathrm{N})$ \\ $x \quad$ annual dimension in the bearing surface \\ $z \quad$ axial coordinate in the bearing surface annual direction in the bearing surface $(\theta=X / R b)$, (degree)}

\section{Green symbols}

$\Delta e \quad$ the change in (e) value due to excitation, (m)

$\Delta \varphi \quad$ the change in $\varphi$ value, (degree)

$\delta \quad$ tilt angle of the pad, (degree)

$\eta \quad$ lubricant viscosity, $(\mathrm{Pa} . \mathrm{sec})$

$\varphi \quad$ attitude angle, (degree)

\section{INTRODUCTION}

The stiffness coefficients existence is a response of the lubricant film to the external forces. The bearing stiffness basically is described by four coefficients. Two of them are essential (principal) stiffness coefficients and the other two are secondary (cross coupling) stiffness coefficients [1]. For a higher accuracy and assessment, for the bearing performance, $8,12,16,32$, or even more numbers of coefficients may be determined. In addition to that, the lubricant film offers a damping action to any external disturbance. This damping action is also described by four coefficients or more. These coefficients (stiffness and damping coefficients) are very commonly named dynamic coefficients or dynamic characteristics of the bearing. These coefficients control the bearing stability so their assessment is necessary to predict the bearing stability. High values for principal coefficients are a positive sign for a high stability while a high value for the cross coupling stiffness coefficients are responsible for disturbing the bearing stability. This is because its displacement is perpendicular to the force direction and so it causes Journal disturbance, journal whirl and other consequences, which end with resonance of the bearing system early at low journal speed [2].

The conventional bearing offers a high value for the cross coupling stiffness coefficients compared with the tilted pad bearing. Therefore, it cannot withstand in a high Journal speed and hence it is not desirable. And the alternative is the tilted pad bearing that introduced at the forties of the last century, which offer a high stability at a high journal speed [3].

\section{MATHEMATICAL EXPRESSIONS FOR THE STIFFNESS COEFFICIENTS}

In the journal bearing, the journal center moves in the $(\mathrm{X}, \mathrm{Y})$ plane following the locus shown on Fig. 1.
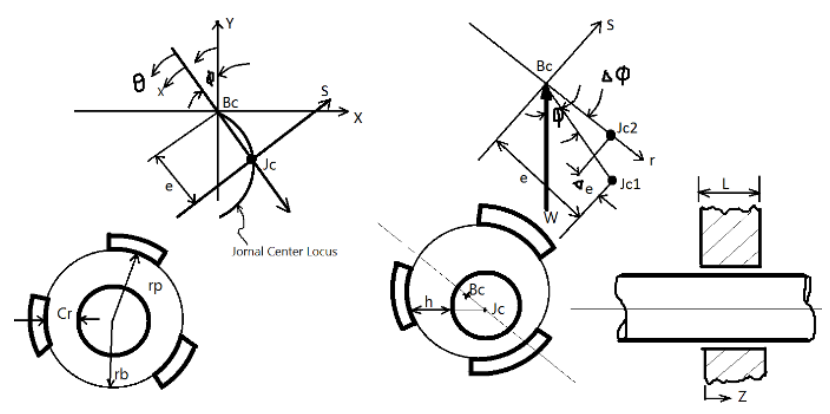

Fig. 1. Non-circular bearing.

The induced forces in the lubricant film could be analyzed in either access, $(X, Y)$ or $(s, r)$, therefore the stiffness coefficients can be expressed in either axis's. In this work, these coefficients are derived for $(s, r)$ axis using the following expressions $[4,5]$.

$$
\begin{aligned}
& F_{r}=\frac{\partial F_{r}}{\partial e} \Delta e+\frac{\partial F_{r}}{e \partial \varphi} e \Delta \varphi \\
& F_{s}=\frac{\partial F_{s}}{\partial e} \Delta e+\frac{\partial F_{s}}{e \partial \varphi} e \Delta \varphi \\
& K_{r r}=\frac{\partial w}{\partial e} \cos \varphi-w \frac{\partial \varphi}{\partial e} \sin \varphi \\
& K_{s s}=\frac{w}{e} \cos \varphi \\
& K_{r s}=\frac{-w}{\varepsilon} \sin \varphi \\
& K_{s r}=\frac{\partial w}{\partial e} \sin \varphi-w \frac{\partial \varphi}{\partial e} \sin \varphi
\end{aligned}
$$

Then to find the values of these coefficients, the "finite perturbation concept" method is used [5].

In this method, it is assumed that a limited journal excitation is happened. Then the stiffness coefficients are calculated based on the finite differences for the forces corresponding to a finite difference in the displacements using a mathematical form based on Taylor series for varying forces. 
Table1

Bearing dimensions and journal speed.

\begin{tabular}{lll}
\hline Symbol & Value & Unit \\
\hline $\mathrm{Rb}$ & 0.025 & $\mathrm{~m}$ \\
$\mathrm{Cr}$ & 0.00004375 & $\mathrm{~m}$ \\
$\mathrm{Rp}$ & 0.025 & $\mathrm{~m}$ \\
$\mathrm{~L}$ & $0.05,0.025$ & $\mathrm{~m}$ \\
$\mathrm{~N}$ & 10000 & $\mathrm{rpm}$ \\
$\eta$ & 0.04 & degree \\
$\delta$ & $0.01,0.012,0.013$ & degree \\
$\theta p$ & $36,30,25.71,22.5,20,18$ & degree \\
\hline
\end{tabular}

\section{SOLVING REYNOLDS EQUATION}

Two dimensional form of Reynolds equation is used:

$\frac{\partial}{\partial x}\left(\frac{h^{3}}{\eta} \frac{\partial p}{\partial x}\right)+\frac{\partial}{\partial z}\left(\frac{h^{3}}{\eta} \frac{\partial p}{\partial z}\right)=6 U \frac{\partial h}{\partial x}$

The governing equation for the lubricant film thickness $(h)$ is:

$$
\begin{aligned}
& h=\operatorname{Cr}(1+n \cos \theta)-x \tan \delta \\
& x=R_{p} \times \theta \\
& \frac{\partial h}{\partial x}=\left[\operatorname{Cr} \frac{n}{R_{p}} \sin \left(\frac{x}{R_{p}}\right)\right]+\tan \delta
\end{aligned}
$$

Reynolds equation is solved numerically using the finite difference technique of five nodes scheme. Afterward the pressure at each node is estimated and then the four coefficients of stiffness's are calculated using 3,4 and 5 pads respectively. And for the three pads type, three tilting angles for the pads are analyzed. These angles are $\delta=0.010^{\circ}, \delta=0.01^{\circ}$ and $\delta=0.012^{\circ}$. Then the results are obtained and the graphs are drawn.

\section{RESULTS AND DISCUSSION}

Referring to Figs. 2-5, the relations between the stiffness coefficients $K_{\mathrm{rr}}, K_{\mathrm{sr}}, K_{\mathrm{ss}}$ and $K_{\mathrm{rs}}$, respectively with the eccentricity ratio $(n)$ representing a comparison between this work and [7] results (both are conventional bearings).

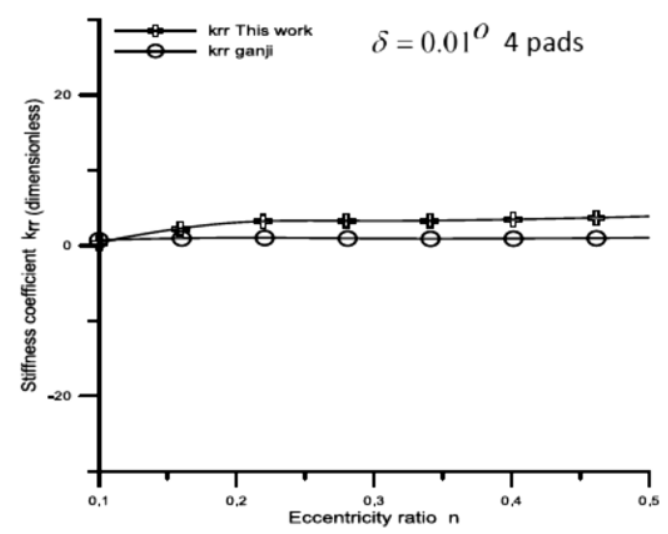

Fig. 2. Variation of $K \mathrm{rr}$ with eccentricity ratio $(n)$.

This comparison was achieved in order to verify the accommodated solution method and approach, if it is acceptable or not. From these figures it could be seen that, both have the same trends which confirm the validity of the solution method. Generally speaking, these coefficients have a higher value for the present work than the [7] results.

This difference between them is expected due to the difference in the geometry dimensions and the work conditions between the present work and Gangi work, therefore the comparison is strictly valid for the trends only, which are the same for both.

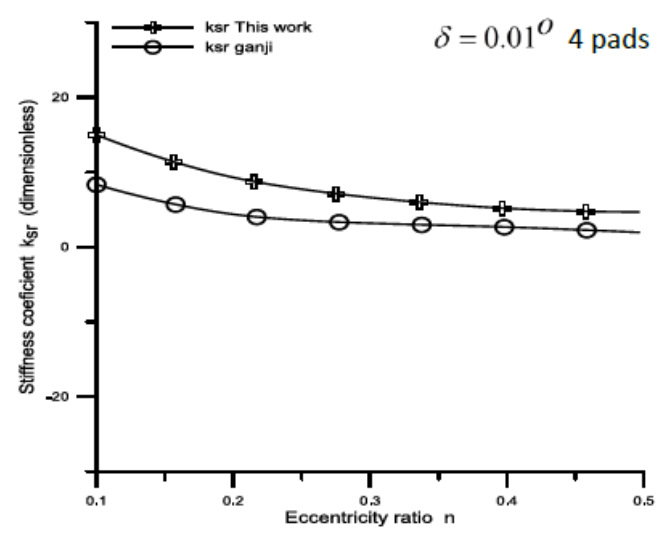

Fig. 3. Variation of $K s \mathrm{r}$ with eccentricity ratio $(n)$.

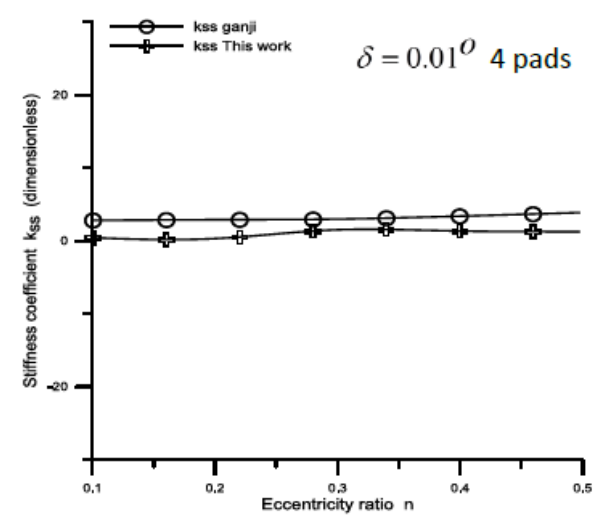

Fig. 4. Variation of $K$ ss with eccentricity ratio $(n)$.

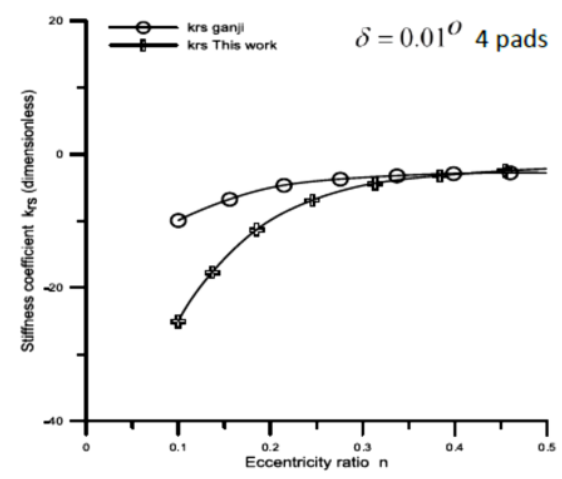

Fig. 5. Variation of $K r s$ with eccentricity ratio (n).

Figs. 6 and 7 show the variation of the stiffness coefficients against the eccentricity ratio, for conventional bearing and a tilted pad bearing, respectively, (both were modeled and studied in this work, both have the same dimensions and work conditions). From these figures it could be seen the differences in the stiffness coefficients values between them. These differences (for the interest of the tilted pads type) are (for $\mathrm{n}=0.4$ ) are $+28 \%,+375 \%$, 
$+270 \%$ and $-100 \%$ for $K_{\mathrm{sr}}, K_{\mathrm{rr}}, K_{\mathrm{ss}}$ and $K_{\mathrm{rs}}$ respectively. All the coefficients values for the tilted pads bearing are higher than that of the conventional one, except Ksr value is decreased. And this is a positive sign for improvement of stability as mentioned early in this study. Also these figures show that $K$ sr and $K \mathrm{rr}$ are exchanged the positions and decreased, which is also another sign for stability improvement $[1,2,8]$.

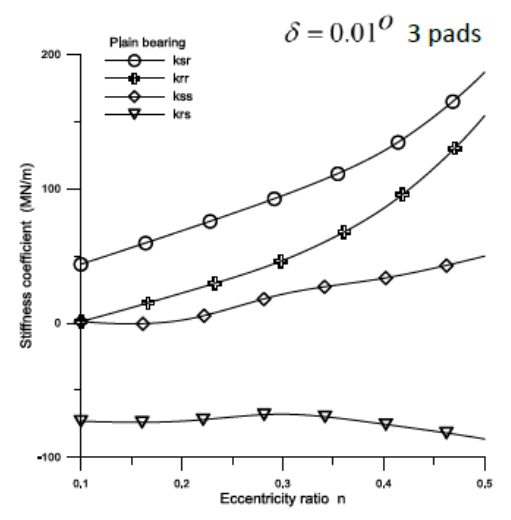

Fig. 6. Stiffness coefficients variation with the eccentricity ratio $(n)$ for conventional bearing.

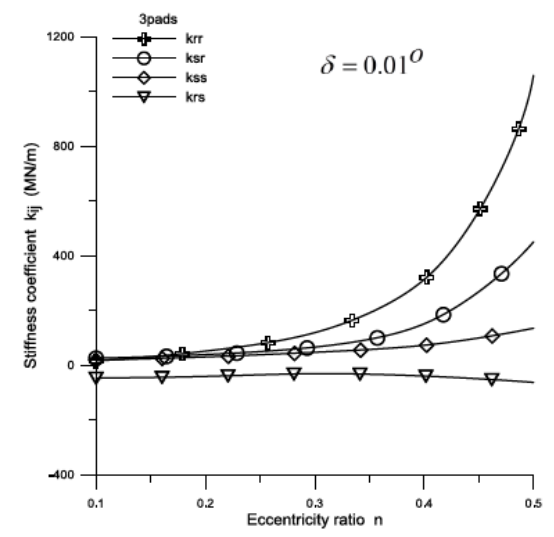

Fig. 7. Stiffness coefficients variation with the eccentricity ratio $(n)$ for tilted pads bearing.

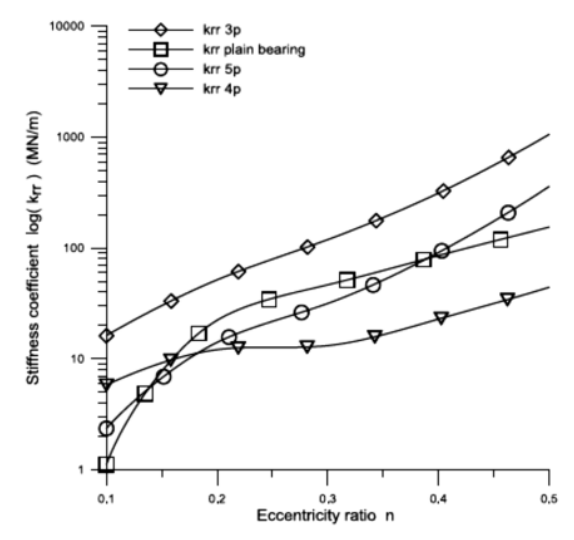

Fig. 8. Variation of $K \mathrm{rr}$ for different number of pads against eccentricity ratio $(n)$.

Figs. 8-11 show the variation of the stiffness coefficients with the eccentricity ratio $(n)$ for different numbers of pads, also for the conventional bearing. Three pads type among the three different models of the tilted pad bearing gave the highest values of all the four stiffness coefficients. While the two other types exchanged the positions except for $\left(K_{\mathrm{rs}}\right)$, four pads type gave a higher coefficient value than the five pads type. The conventional bearing gave the highest value among all for $(K r s)$. And this is not considered as a meretricious for the conventional bearing since it disturbs stability $[1,2,8]$. The conflict and interaction of the curves of four and five pads types is a result of distributing the pads around the journal gave a random result for the bearing characteristics.

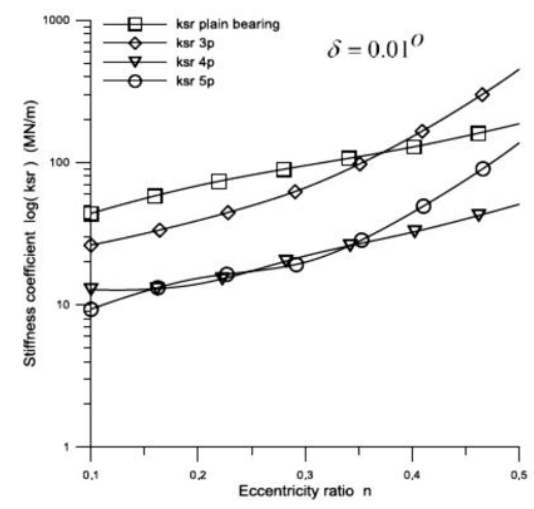

Fig. 9. Variation of $K$ sr for different number of pads against eccentricity ratio $(n)$.

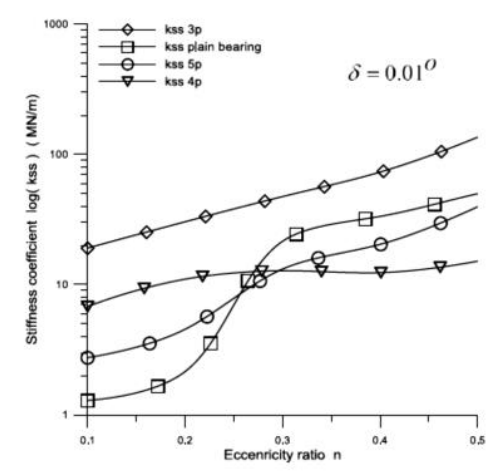

Fig. 10. Variation of $K$ ss for different number of pads against eccentricity ratio $(n)$.

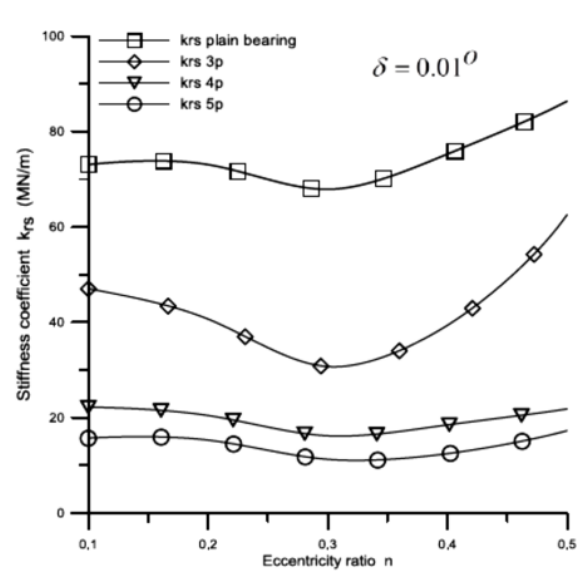

Fig. 11. Variation of $K$ rs for different number of pads against eccentricity ratio $(n)$.

Figs. 12-15 show the variation of the stiffness coefficients against the tilting angle (delta) of the pads. These figures show that, increasing the tilting angle gives an increase of the stiffness coefficients. These increase (for $\mathrm{n}=0.4$ and changing the tilt angle from 0.010 to 0.011 then 


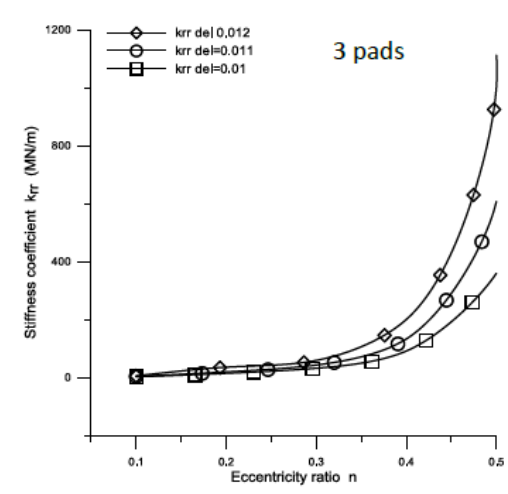

Fig. 12. Variation of $K \mathrm{rr}$ for different pad angles against eccentricity ratio $(n)$.

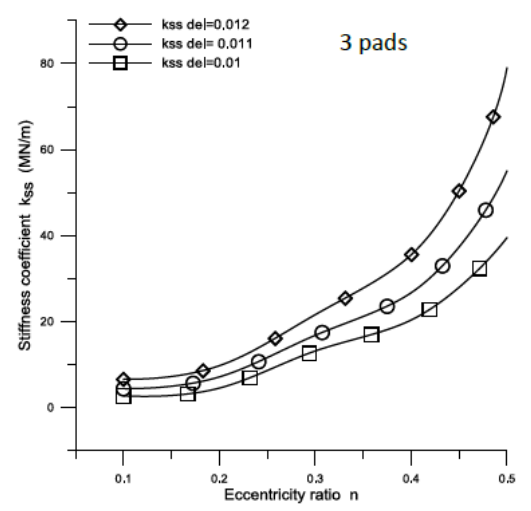

Fig. 13. Variation of $K$ ss for different pad angles against eccentricity ratio $(n)$.

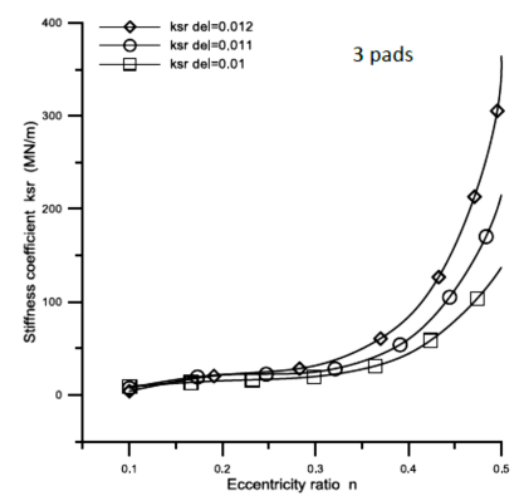

Fig. 14. Variation of $K$ sr for different pad angles against eccentricity ratio $(n)$.

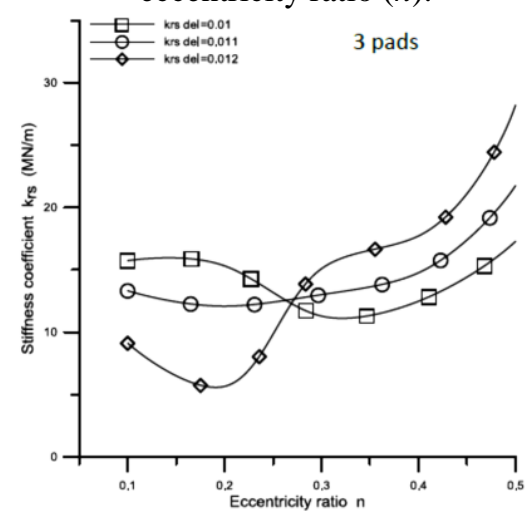

Fig. 15. Variation of $K r$ for different pad angles against eccentricity ratio $(n)$.

to 0.012 , respectively) are, $K_{\mathrm{rr}}=+50 \%,+47$ and $K_{\mathrm{ss}}=$ $+40 \%,+32 \%$ and $K_{\mathrm{sr}}=+33 \%,+42 \%$ and $K_{\mathrm{rs}}=+15 \%$,
$+20 \%$. And it could be noted that changing the tilt angle of the pads is not a good way to improve stability since this cause an increase of both types of stiffness coefficients, principal and cross coupling. This is because increasing the cross coupling coefficients making the stability worse as mentioned early in this paper [2]. While increasing the principal coefficients improve stability [1]. Therefore, improving stability by changing the number of pads is a better solution. And also probably changing the load line is another alternative solution for improving stability.

\section{CONCLUSIONS}

1. The pad bearing has a higher value for the principal stiffness coefficients $\left(K_{\mathrm{rr}} \& K_{\mathrm{ss}}\right)$ and this justify the high stability of the tilted pad bearing compared with the conventional one.

2. For this bearing dimensions, three pads type is the best choice among the three types (3,4 and 5), regarding the bearing stiffness and stability.

3. Increasing the tilting angle of the pads is not a good way to improve stability since it increases both types of stiffness coefficients

\section{RECOMMENDATIONS}

1. Carry out an experimental work in order to reinforce these theoretical results.

2. Study the damping coefficients and their effect on the bearing stability.

\section{REFERENCES}

[1] Qiu ZL. A theoretical and experimental study on dynamic characteristics of journal bearings. Ph.D. Thesis: Wollongong University; Wollongong NSW 2522, Australia: 1995.

[2] Glienicke J, Han D-C, Leonhard M. Practical determination and use of bearing dynamic coefficients. Tribology International 1980; 13 (6): 297-309.

[3] Balupari RS. Validation of finite element program for journal bearing static and dynamic properties. MSc. Thesis. University of Kentuky; Lexington, USA: 2004.

[4] Andres L. Dynamics of a rigid rotor-fluid film bearing system. MSc. Thesis. Texas A\&M University; Texas, USA: 2000.

[5] Martelli F, Manfrida G. A new approach to the theoretical calculation of the dynamic coefficients of tilting-pad bearings. Wear 1981; 70 (2): 249-258.

[6] Majed RH. Load line direction and bearing length effects on the tilting 4-pad bearing performancePerformance. Engineering and Technology Journal 2009; 27 (9): 1691-1700.

[7] Ganji TR, Kakoty S. Effect of cylindrical texture on dynamic characteristics of journal bearing. International Journal of Recent Advances in Mechanical Engineering 2014; 3 (4): 1.13.

[8] He M, Cloud CH, Byrne JM, Vázquez JA. Fundamentals of fluid film journal bearing operation and modeling. Asia Turbomachinery \& Pump Symposium 2016 Proceedings: Texas A\&M University. Turbomachinery Laboratory; 2016. 